\title{
Antifungal Effects of Zataria multiflora Essential Oil on the Inhibitory Growth of some Postharvest Pathogenic Fungi
}

\author{
Mahboobeh NASSERI ${ }^{1}$, Hossein AROUIEE ${ }^{1 *}$, Shiva GOLMOHAMMADZADEH ${ }^{2}$, \\ Mahmoud Reza JAAFARI ${ }^{3}$, Hossein NEAMATI ${ }^{1}$ \\ ${ }^{1}$ Ferdowsi University of Mashhad, Faculty of Agriculture,Department of Horticulture Science, Mashhad, Iran; aroiee@ferdowsi.um.ac.ir (*orrespondingauthor), \\ Mabboobeh_naseri@yahoo.com;Nematish@yahoo.com \\ 2Mashhad University of Medical Sciences, School of Pharmacy, Biotechnology Research Center, Mashhad, Iran; Golmohamadzadehsh@mums.ac.ir \\ ${ }_{3}^{3}$ Mashhad University of Medical Sciences, School of Pharmacy, Nanotechnology Research Center, Mashhad, Iran;jafarimr@mums.ac.ir
}

\begin{abstract}
The present study aimed to determine minimum inhibitory concentration and minimum fungicidal concentration of the essential oil of Zataria multiflora to control Alternaria solani, Rhizoctonia solani, Rhizopus stolonifer, Aspergillusflawus, Aspergillus ochraceus and Aspergillus niger. The essential oil of Zataria multiflora was tested in vitro on PDA (malt extract agar medium) with eight concentrations: $0,10,50,100$, 200, 300, 400, 500, 600, 700, 800, 900 and $1000 \mathrm{ppm}$. This investigation followed the completely randomized design (CRD) with three replications. GC-MS evaluations of the essential oil revealed that thymol (35\%), carvacrol (34\%), cymene-p (9.89\%), gamma-terpinene (5.88\%) and alpha-pinene (4.22\%) were the main compounds of Zataria multiflora oil. The results showed that the essential oil of Zataria multiflora has antifungal activity; the lowest inhibition (75\%) was observed in the $A$. niger, while the highest inhibition (95.3\%) was observed in A. solani. Minimum inhibitory concentration for A. solani, R solani, R. stolonifer, A. flawus, A. ochraceus and A. niger was 200, 200, 200, 300, 300 and $200 \mathrm{ppm}$ respectively. In addition, the present results showed that minimum fungicidal concentration (MFC) for $A$. solani, $R$. solani, R.stolonifer, A. niger and A.ochraceus was 600,400,300,900 and $700 \mathrm{ppm}$ respectively and none of the tested concentrations were fatal for A. flavus. A. solani and $R$. solani showed a strong sensitivity to Zataria multiflora essential oil at all concentrations. Findings of the current study suggest that essential oils of Zataria multiflora could be used for control of postharvest phytopathogenic fungi on fruits or vegetables.
\end{abstract}

Keywords: carvacrol, thymol, fungicidal, fungistatic, Shiraz thyme

\section{Introduction}

Fruits and vegetables are often subject to varying levels of microbial decay during storage. Pathogenic fungi usually infect the host through wounds and cause significant economic losses in the commercialization stage (Gatto et al., 2011).

The use of manufactured chemicals as fungicides is a main method to prevent or delay diseases and the post harvest rot is well known. Outspread use of fungicides has significant disadvantage including increased cost, worry about fungicides residues on crop, as well as risk for human health and environment (Nikos and Costas, 2007). As alternatives to synthetic fungicides, natural crop protective products are currently in the highlight (Combrinck et al., 2011). These include plant essential oils, a number of which have been reported to show antimicrobial activity against a wide array of plant pathogenic agents.
Essential oils are represent a defence mechanism against pathogens and pests, produced in different plant section and they also have been shown to own antimicrobial and antifungicidal properties (Znini et al., 2011). Several studies have investigated the antifungal properties of essential oils against postharvest pathogens (Giamperi et al., 2002; Bouchra et al., 2003; Bagamboula et al., 2004).

Zataria multiflora belongs to Laminaceae family and is mainly distributed in Iran, Pakistan and Afghanistan (Ali et al., 2000; Hosseinzadeh et al., 2000). It is greatly used for medicinal and spice uses in these countries. Commonly named Avishan Shirazi in Iran, $Z$. multiflora has various traditional uses such as antiseptic, anesthetic and antispasmodic (Zargari, 1990).

The antimicrobial properties of essential oils are principally related to their phenolic compounds (Bagamboula et al., 2004). Carvacrol and thymol are the main components of Zataria multiflora essential oil that are phenolic compounds (AlizadehAlteh et al., 2010). 
Table 1. Chemical composition of $Z$. multiflora essential oil

\begin{tabular}{|cccc}
\hline No & Components & $\begin{array}{c}\text { Amount } \\
(\%)\end{array}$ & $\begin{array}{c}\text { Retention index } \\
(\mathrm{RI})\end{array}$ \\
\hline 1 & Alpha-Thujene & 0.36 & 930 \\
2 & Alpha-Pinene & 4.22 & 939 \\
3 & Camphene & 0.1 & 954 \\
4 & Beta-Pinene & 0.34 & 979 \\
\hline 5 & Beta-Myrcene & 1.01 & 990 \\
6 & Alpha-Phellandrene & 0.19 & 1002 \\
7 & Alpha--Terpinene & 1.26 & 1017 \\
8 & Cymene<p-> & 9.89 & 1024 \\
\hline 9 & $1,8-$ Cineole & 0.37 & 1031 \\
10 & Gamma-Terpinene & 5.88 & 1059 \\
\hline 1 & Linalooll & 0.37 & 1096 \\
12 & Terpinene-4-ol & 0.36 & 1177 \\
13 & Terpineneol<gama> & 0.29 & 1199 \\
14 & Thymyl Methyl Ether & 0.41 & 1235 \\
15 & Carvacrol Methyl Ether & 0.73 & 1244 \\
16 & Thymoquinone & 0.63 & 1248 \\
\hline 17 & Thymol & 35.3 & 1289 \\
18 & Carvacrol & 33.9 & 1299 \\
\hline 19 & Trans-Caryophyllene & 1.12 & 1417 \\
\hline 20 & Aromadendrene & 0.36 & 1439 \\
21 & Ledene & 0.22 & 1475 \\
\hline & & & \\
\hline
\end{tabular}

Based on the distribution and abundance of Zataria multiflora in Iran, the studies on these plants in the term of their antifungal properties provide a solid ground that their results might be used to replace the fungicides of natural origin to control the postharvest diseases of crops, and this can lead to significant decreasing of the fungicides application and thus minimising their effects. Therefore, the objective of the present study was to evaluate the in vitro activity of plant essential oils from Zataria multiflora against postharvest fungal pathogens (Alternaria solani, Rhizoctonia solani, Rhizopus stolonifer, Aspergillus flavus, Aspergillus ochraceus and Aspergillus niger) and to determine the minimum inhibitory concentration and the minimum fungicidal concentration of Zataria multiflora.

\section{Materials and Methods}

\section{Essential oils and fungi species}

The essences of $Z$. multiflora were obtained from Barij Essence Pharmaceutical Co (Kashan, Iran). The strain of the studied fungus was obtained from the Agriculture and Natural Resources Research Center of Khorasan Razavi (Mashhad, Iran).

\section{Gas chromatography/mass spectrometry and component identification}

Gas chromatography/mass spectrometry (GC/MS) analysis was carried out in a Varian 3400 GC/MS (California, USA) system equipped with a DB-5 fused silica column $(30 \mathrm{~m} \times 0.25 \mathrm{~mm}$ i.d., film thickness $0.25 \mu \mathrm{m}$; J and W Scientific). The oven temperature was raised from 50 to $240{ }^{\circ} \mathrm{C}$ at a rate of $4^{\circ} \mathrm{C} \mathrm{min}{ }^{-1}$, the transfer line temperature was $260^{\circ} \mathrm{C}$, the carrier gas was helium at a linear velocity of $31.5 \mathrm{~cm} \mathrm{~s}^{-1}$, the split ratio was $1: 60$, the ionization energy was $70 \mathrm{eV}$. The components of the oils were identified by comparison of their mass spectra with those of a computer library or with those of authentic compounds and confirmed by comparison of their retention indices with those of authentic compounds or with data published in the literature. The retention indices were calculated for all volatile constituents using a homologous series of alkanes.

Antifungal effects of Zataria multiflora essential oil on mycelia radial growth by in vitro method

Antifungal activity was studied using a contact assay (in vitro) that produced hyphal growth inhibition. The assay was previously used for essential oil treatment on potato dextrose agar (PDA) medium by the 'solution method' (SM) (Özden and Bayindirli, 2002). Briefly, the essential oil was dissolved in $50 \mathrm{ml} \mathrm{L}-{ }^{1}$ Tween $80 /$ water solution and the required amounts of these solutions were added to individual Petri dishes containing $20 \mathrm{~mL}$ of PDA medium at $45^{\circ} \mathrm{C}$. Then a $0.5 \mathrm{~mm}$ disc of mycelium was placed on the PDA medium in each dish. The treated media were incubated at $27^{\circ} \mathrm{C}$ and mycelia growth was measured daily. The inhibitory percentage (IP) was determined from the formula $\mathrm{IP}=[(d \mathrm{c}-d \mathrm{t}) / d \mathrm{c}] \times 100$, where $d c$ is the mycelium diameter in the control Petri dish and $d t$ is the mycelium diameter in the essential oil treated Petri dish.

\section{Nature of toxicity of the essential oil}

The fungi-toxicity (fungistatic/fungicidal) of the essential oil was evaluated using the technique described by Thompson (1989). Different experiments were performed to demonstrate the toxicity nature of the oil at its minimum inhibitory concentration (MIC) and minimum fungicidal concentration (MFC) by the poisoned food technique assay. On day 7 , the inhibited fungal discs of the treatment groups were acquired, washed with sterilized water and separately reinoculated into Petri plates containing fresh medium which were similarly incubated. On day 7, the assessment for the revival of growth of the reinoculated fungal discs was performed based on the observation (presence or absence) of mycelia growth.

\section{Statistical analysis}

Data were analysed statistically using analysis of variance (ANOVA) and differences among the means were determined for significance at $\mathrm{P}<0.05$ using Duncan's test (by MSTATC software). The experiment was arranged as a completely randomized design (CRD) with three replications for each treatment.

\section{Results}

\section{Chemical compositions of essential oil}

The chemical composition of the essential oils was determined by GC/MS analysis. The identified components are given in Table 1 with their relative percentages. The twenty one compounds were characterized in the oil of $Z$. multiflora, making up of $98.71 \%$ of the oil. Major components of Shiraz thyme oil were: thymol (35\%), carvacrol (34\%), cymene.p (9.89\%), gamma-terpinene $(5.88 \%)$ and alpha-pinene $(4.22 \%)$ (Fig. 1). The major components of Shiraz thyme (carvacrol, thymol, p-cymene and linalool) have key roles in regard to the antifungal activity (Burt, 2004; Omidbeygi, et al., 2007; Solaimani, 2009). 
414

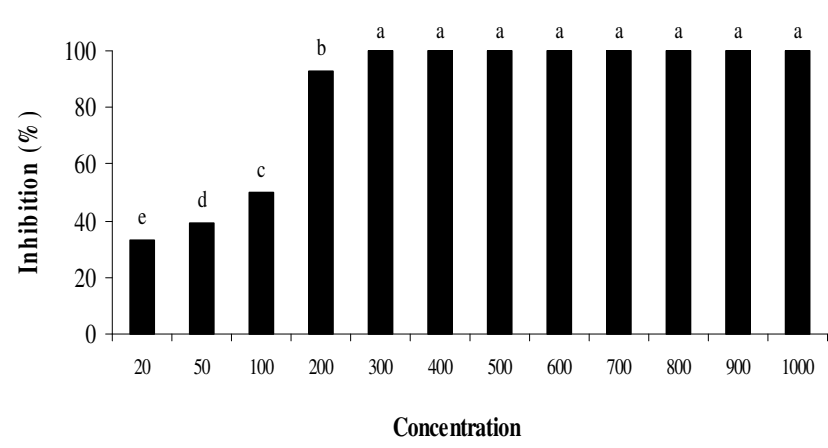

Fig. 1. Effect of different concentrations of Zataria multiflora essential oil on the inhibition percentage of fungus Alternaria solani, Rhizoctonia solani, Rhizopus stolonifer, Aspergillus flavus, Aspergillus ochraceus and Aspergillus niger. Different letters above columns indicate significant differences according to Duncan's multiple range tests at $\mathrm{P} \leq 0.01$

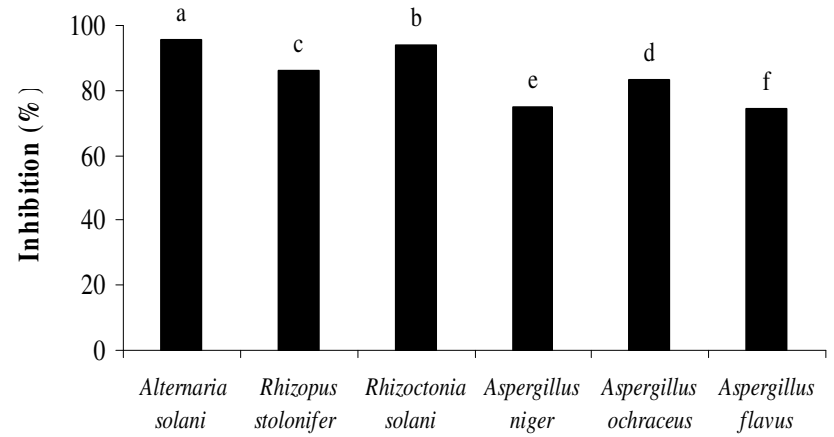

Fig. 2. Effect of Zataria multiflora essential oil on the inhibition percentage of fungus Alternaria solani, Rhizoctonia solani, Rhizopus stolonifer, Aspergillus flavus, Aspergillus ochraceus and Aspergillus niger. Different letters above columns indicate significant differences according to Duncan's multiple range tests at $\mathrm{P} \leq 0.01$

Table 2. Effect of different concentrations of Zataria multiflora essential oil on the inhibition percentage of fungus Alternaria solani, Rhizoctonia solani, Rhizopus stolonifer, Aspergillusflawus, Aspergillus ochraceus and Aspergillus niger

\begin{tabular}{|c|c|c|c|c|c|c|}
\hline Concentration (ppm) & R. stolonifer & R. solani & A. solani & A. flavus & A. ochraceus & A. niger \\
\hline Control (0) & - & - & - & - & - & - \\
\hline 20 & (s) $69 \mathrm{e}$ & (s) $22 \mathrm{k}$ & (s) $77 \mathrm{~d}$ & (s) $0 \mathrm{~m}$ & (s) $30 \mathrm{j}$ & (s) $0 \mathrm{~m}$ \\
\hline 50 & (s) $67 \mathrm{f}$ & (s) $44 \mathrm{~h}$ & (s) $83 \mathrm{c}$ & (s) $0 \mathrm{~m}$ & (s) $42 \mathrm{i}$ & (s) $0 \mathrm{~m}$ \\
\hline 100 & (s) $89 \mathrm{~b}$ & (s) $66 \mathrm{f}$ & (s) $83 \mathrm{c}$ & (s) 111 & (s) $50 \mathrm{~g}$ & (s) $0 \mathrm{~m}$ \\
\hline 200 & (s) $100 \mathrm{a}$ & (s) $100 \mathrm{a}$ & (s) $100 \mathrm{a}$ & (s) $78 \mathrm{~d}$ & (s) $78 \mathrm{~d}$ & (s) $100 \mathrm{a}$ \\
\hline 300 & (c) $100 \mathrm{a}$ & (s) $100 \mathrm{a}$ & (s) $100 \mathrm{a}$ & (s) $100 \mathrm{a}$ & (s) $100 \mathrm{a}$ & (s) $100 \mathrm{a}$ \\
\hline 400 & (c) $100 \mathrm{a}$ & (c) $100 \mathrm{a}$ & (s) $100 \mathrm{a}$ & (s) $100 \mathrm{a}$ & (s) $100 \mathrm{a}$ & (s) $100 \mathrm{a}$ \\
\hline 500 & (c) $100 \mathrm{a}$ & (c) $100 \mathrm{a}$ & (s) $100 \mathrm{a}$ & (s) $100 \mathrm{a}$ & (s) $100 \mathrm{a}$ & (s) $100 \mathrm{a}$ \\
\hline 600 & (c) $100 \mathrm{a}$ & (c) $100 \mathrm{a}$ & (c) $100 \mathrm{a}$ & (s) $100 \mathrm{a}$ & (s) $100 \mathrm{a}$ & (s) $100 \mathrm{a}$ \\
\hline 700 & (c) $100 \mathrm{a}$ & (c) $100 \mathrm{a}$ & (c) $100 \mathrm{a}$ & (s) $100 \mathrm{a}$ & (c) $100 \mathrm{a}$ & (s) $100 \mathrm{a}$ \\
\hline 800 & (c) $100 \mathrm{a}$ & (c) $100 \mathrm{a}$ & (c) $100 \mathrm{a}$ & (s) $100 \mathrm{a}$ & (c) $100 \mathrm{a}$ & (s) $100 \mathrm{a}$ \\
\hline 900 & (c) $100 \mathrm{a}$ & (c) $100 \mathrm{a}$ & (c) $100 \mathrm{a}$ & (s) $100 \mathrm{a}$ & (c) $100 \mathrm{a}$ & (c) $100 \mathrm{a}$ \\
\hline 1000 & (c) $100 \mathrm{a}$ & (c) $100 \mathrm{a}$ & (c) $100 \mathrm{a}$ & (s) $100 \mathrm{a}$ & (c) $100 \mathrm{a}$ & (c) $100 \mathrm{a}$ \\
\hline
\end{tabular}

Different letters indicate significant differences according to Duncan's multiple range tests at $\mathrm{P} \leq 0.01$.

These results are in agreement with those published by Omidbeygi et al. (2007), Suhr and Nielsen (2003) and Solaimani et al. (2009) who reported that the major components of thyme essential oil are thymol, carvacrol, and á-pinene.

Inbibitory effect of the Z. multiflora essential oil on the studied fungus

The effects of different concentrations of the essential oils on the inhibition percentage of fungus are shown in Fig. 1. The highest inhibition (100\%) was observed in the $300 \mathrm{ppm}$ and more than it, while the lowest (33\%) inhibition was obtained with $20 \mathrm{ppm}$ essential oil of Zataria multiflora to control of the tested fungus. These results indicate that the percentage inhibition of mycelia growth increased with increasing concentrations of $Z$. multiflora essential oil for all fungus tested. The present results suggested that the essential oil of $Z$. multiflora has a significant activity $(\mathrm{P}<0.05)$ and inhibited the mycelia growth of all fungus.

The effects of essential oils on the inhibition percentage of fungus of $A$. solani, $R$. solani, $R$. stolonifer, A. flavus, $A$. ochraceus and $A$. niger are shown in Fig. 2 . The lowest inhibition (75\%) was observed in the $A$. niger and the highest inhibition (95.3\%) was observed in $A$. solani. It was clear that $A$. solani and $R$. solani showed a high sensitivity to Zataria multiflora essential oil at all concentrations.

The lowest inhibition (0\%) was observed in the concentrations of 20,50 and $100 \mathrm{ppm}$ in $A$. niger and concentrations of 20 and $50 \mathrm{ppm}$ in A. flavus. Also the highest inhibition (100\%) was observed in the $200 \mathrm{ppm}$ and more than it in A. solani, R. solani, R. stolonifer, A. niger and $300 \mathrm{ppm}$ and more than it in $A$. flavus and $A$. ochraceus (Table 2). Also, the results showed that minimum inhibitory concentration (MIC) for A. solani, R. solani, R. stolonifer, $A$. flavus, A. ochraceus and A.niger was 200, 200, 200, 300, 300 and $200 \mathrm{ppm}$ respectively (Table 2 ).

Minimum fungicidal concentration (MFC) for A.solani, R. solani, R.stolonifer, A. niger and A. ochraceus was 600, 400, 300,900 and $700 \mathrm{ppm}$ respectively and of the concentrations were fatal for A. flavus (Table 2). This indicated that this oil has fungistatic effect on $A$. flavus. 


\section{Discussion}

Zataria multiflora is a thyme-like plant that wildly grows in central and southern parts of Iran (Ali et al., 2000). It is a member of the Labiate family to which mint, rosemary and several other medically useful plants also belong. The Shiraz thyme essential oil used in the present study consisted of 21 components of which thymol (35\%) and carvacrol (34\%) were the major components. These results are in agreement with those of Soleimani et al. (2009) who reported that the major components of thyme essential oil are thymol, carvacrol and linalool. Mirzabagheri et al. (2014) reported that Zataria multiflora consisted of 25 components which thymol (13\%) and carvacrol (50\%) were the most abundant ones. Shaffiee and Javidnia (1997) found that the major components of Zataria multiflora oil prepared from Yazd Province of Iran were carvacrol (61.3\%) and thymol (25.18\%). Sharififar et al. (2007) observed that thymol (37.6\%), carvacrol (33.6\%) were the main components of Zataria multiflora oil. The composition of the essential oil of plants can change extensively depending upon the geographical conditions, variety, age of the plant and due to the method of drying and extraction of the oil (Valero and Salmeron, 2003; Bagamboula et al., 2004).

Essential oils complex mixtures of volatile compounds are produced by plants as secondary metabolites. The antibacterial and antifungal properties of essential oils have been known and used for duration (Danuta Kalemba et al., 2012). The power of any biological activity of essential oils is severely connected with the oil composition and especially with the content of some very active constituents. It is reported that phenols and monoterpenes (thymol and carvacrol, the most phenols found in essential oils) have the highest activity (Bagamboula et al., 2004). Antifungal activities of these compounds have been reported by others (Kalemba and Kunicka, 2003; Chmai et al., 2004; Bagamboula et al., 2004). However, the mechanisms of action of these compounds have not been completely explained. Lis-Balchin and Deans (1997) reported that strong antimicrobial activity could be correlated with essential oils containing high percentage of monoterpenes, thymol and carvacrol.

In the present study, Zataria essential oil showed antifungal activity against the mycelia growth of all the phytogenic fungi studied (Fig. 2). This activity is related to its high levels of oxygenated monoterpenes. Zambonelli et al. (1996) reported that the high activity of monoterpenes against pathogens result from their interference with enzymatic reaction during cell-wall synthesis. The effect of essential oils on microbial growth has been reported by Fung et al. (1977) who thought it may be the result of phenolic compounds in essential oils that cause an alteration in microbial cell permeability by interacting with membrane proteins.

The inhibition rate reached $78 \%$ for $A$. flavus, $A$. ochraceus and $100 \%$ for $A$. solani, R. solani, R. stolonifer and $A$. niger at $200 \mathrm{ppm}$. This indicated that $200 \mathrm{ppm}$ was the minimal inhibitory concentration (MIC) of Shiraz thyme essential oil against $A$. solani, $R$. solani, $R$. stolonifer, $A$. niger and $300 \mathrm{ppm}$ for $A$. flavus, $A$. ochraceus (Table 2). This might be attributable to the mechanism of resistance of the fungi against various substances present in the essential oil. The plant pathogens studied can be classified according to their sensitivity to the oil in the following order: $A$. solani $>R$. stolonifer $>R$. stolonifer $>A$. ochraceus $>A$. niger $>A$. flavus (Fig. 2).

After the transfer of the mycelia disk on plates containing a PDA medium and essence on fresh PDA (without oil) was made, the mycelia of $A$. flavus grew after incubation for seven days. It indicated that this oil has fungistatic effect (no fungicidal activity) on $A$. flavus (Table 2). Gandomi Nasrabadi et al. (2008) reported that MIC of Shiraz thyme essential oil against $A$. flavus was $400 \mathrm{ppm}$ and MFC was 1000 ppm. Mahmoudi et al. (2012) determined the MIC of Shiraz thyme essential oil against Alternaria alternate by the poisoned food technique was $500 \mathrm{ppm}$. The fungicidal nature of the oil indicates its potential economic exploitation as fungi toxicant which has not been reported before (Basti et al., 2007).

\section{Conclusions}

The current results demonstrated that Zataria essential oil had an antifungal activity and may be considered a potential alternative to artificial fungicides for the defend of fruit and vegetable against phytopathogenic fungi. Nevertheless, before it can be marketed the evaluation of the antifungal activity of Zataria multiflora essential oil on in vivo condition is required.

\section{References}

Ali MS, Saleem M, Ali Z, Ahmad VU (2000). Chemistry of Zataria multiflora (Lamiaceae). Phytochemistry 55:933-936.

Alizadeh-Salteh S, Arzani K, Omidbeigi R, Safaie N (2010). Essential oils inhibit mycelial growth of Rhizopus stolonifer. European Journal of Horticultural Science 75(6):278-282.

Burt S (2004). Essential oils: their antibacterial properties and potential applications in foods. International Journal of Food Microbiology 94:223-253.

Bagamboula CF, Uyttendaele M, Debevere J (2004). Inhibitory effect of thyme and basil essential oils, carvacrol, thymol, estragol, linalool and p-cymene towards Shigellasonnei and Shigellaflexneri. Journal of Food Microbiology 21:32-42.

Bouchra C, Achouri M, Hassani LMI, Hmamouchi M (2003). Chemical composition and antifungal activity of essential oils of seven Moroccan Labiate against Botrytis cinera pers. Journal of Ethnopharmacology 89(1):165-169.

Camele I, De Feo V, Altieri L, Mancin E, De Martino L, Luiqi Rana $G$ (2010). An attempt of postharvest orange fruit rot control using essential oils from Mediterranean plants. Journal of Medicinal Food 13:1515-1523.

Chmai N, Chami F, Bennis S, Trouillas J, Remmal A (2004). Antifungal treatment with carvacrol and eugenol of oral candidiasis in immune suppressed rats. Brazilian Journal of Infectious Diseases 8(3):217-226. 
416

Combrinck S, Regnier T, Kamatou GPP (2011). In vitro activity of eighteen essential oils and some major components against common postharvest fungal pathogens of fruit. Industrial Crops and Products 33:344-349.

Droby S (2005). Improving quality and safety of fresh fruit and vegetables after harvest by the use of biocontrol agent and natural materials. International Symposium on Natural Preservatives in Food Systems 709:45-52.

Fung DYC, Taylor S, Kahan J (1977). Effects of butylated hydroxyanisole (BHA) andbutylated hydroxitoluene (BHT) on growth and aflatoxin production of Aspergillus flavus. Journal of Food Safety 1:39-51.

Gandomi Nasrabadi H, Misaghi A, Akhondzadeh A, Bokaei S, Khosravi A, Abbasifar A, Jebelli A (2008). Effect of Zataria multiflora Boiss. essential oil on growth and aflatoxin formation by Aspergillus flavus in culture media and cheese. Food and Chemical Toxicology 47:2397-2400.

Gatto MA, Ippolito A, Linsalata V, Cascarano NA, Nigro F, Vanadia S, Di Venere D (2011). Activity of extracts from wild edible herbs against postharvest fungal diseases of fruit and vegetables. Postharvest Biology and Technology 61:72-82.

Giamperi L, Fraternal D, Ricci D (2002). The in vitro action of essential oils on different organisms. Journal of Essential Oil Research 14:312-318.

Hosseinzadeh H, Ramezani M, Salmani G (2000). Antinoci-ceptive, anti-inflammatory and acute toxicity effects of Zataria multiflora Boiss extracts in mice and rats. Journal of Ethnopharmacology 73:379-385.

Kalemba D, Kunicka A (2003). Antibacterial and antifungal properties of essential oils (a review article).Current Medicinal Chemistry10:813-829.

Lis-Balchin M, Ochocka RJ, Deans SG (1999). Differences in bioactivity between the enantiomers of a -pinene. Journal of Essential Oil Research 11:393-397.

Mahmoudi E, Ahmadi A (2013). Evaluation of Salvia officinalis antifungal properties on the growth and morphogenesis of Alternaria alternata under in vitro conditions. Technical Journal of Engineering and Applied Sciences 3(17):2062-2069.

Mirzabagheri D, Abbaszadeh M, Akbari MM, Derijani S, Sadradini S (2014). Inhibition effects of Zataria multiflora, Eucalyptus camaldulensis and Myrtus communis essential oil on mycelia growth of green mold of orange. International Journal of Advanced Biological and Biomedical Research 2(1):86-99.

Nikos GT, Costas DE (2007). Antifungal activity of lemongrass (Cympopogon citrates L.) essential oil against key postharvest pathogens. Innovative Food Science and Emerging Technologies 8:253-258
Omidbeygi M, Barzegar M, Hamidi Z, Naghdibadi H (2007). Antifungal activity of thyme, summer savory and clove essential oils against Aspergillus xavus in liquid medium and tomato paste. Food Control 18:1518-1523.

Ozden C, Bayindirli L (2002). Effects of combinational use of controlled atmosphere, cold storage and edible coating applications on shelf life and quality attributes of green peppers. Food Research and Technology 21:320-326.

Shaffiee A, Javidnia K (1997). Composition of essential oil of Zataria multiflora. Planta Medica 63:371-372.

Sharififar F, Moshafi MH, Mansouri SH, Khodashenas M, Khoshnoodi M (2007). In vitro evaluation of antibacterial and antioxidant activities of the essential oil and methanol extract of Zataria multiflora Boiss. Food Control 18:800-805.

Solaimani B, Ramezani M, Saharkiz MJ (2009). Biological control of postharvest disease caused by Penicillium digitatum and $P$. italicum on stored citrus fruits by Shiraz thyme essential oil. Advances in Environmental Biology 3:249-254.

Suhr KI, Nielsen PV (2003). Antifungal activity of essential oils evaluated by two different application techniques against rye bread spoilage fungi. Journal of Applied Microbiology 94:665674.

Thompson DP (1989). Fungitoxic activity of essential oil components on food storage fungi. Mycologia 81:151-153.

Tzortzakis NG (2009). Impact of cinnamon oil-enrichment on microbial spoilage of fresh produce. Innovative Food Science and Emerging 10:97-102.

Ultee A, Bennik MHJ, Moezelaar R (2002). The phenolic hydroxyl group of 415 carvacrol is essential for action against the foodborne pathogen Bacillus cereus. Applied and Environmental Microbiology 68:1561-1568.

Valero M, Salmeron MC (2003). Antibacterialactivity of 11 essential oils against Bacillus cereus in tyndallized carrot broth. International Journal of Food Microbiology 85:73-81.

Zargari A (1990). Medical plants. (4 $4^{\text {th }}$ ed). Tehran University Publication Co pp 1-57.

Zambonelli A, D’Aulerio AZ, Bianchi A (1996). Effects of essential oils on phytopathogenic fungi in vitro. Journal of Phytopathology 144:491-494.

Znini M, Cristofari G, Majidi L, Mazouz H, Tomi P, Paolini J, Costa J (2011). Antifungal activity of essential oil from Asteriscus graveolens against postharvest phytopatogenic fungi in apples. Natural Product Communications 6:1763-1768. 